\title{
Correction of clivoaxial angle deformity in the setting of suboccipital craniectomy: technical note
}

\author{
Daniel Felbaum, MD, Steven Spitz, MD, and Faheem A. Sandhu, MD, PhD \\ Department of Neurosurgery, Medstar Georgetown University Hospital, Washington DC
}

A subset of patients with Chiari Type I malformation may develop neurological dysfunction secondary to an abnormally obtuse clivoaxial angle (CXA) and clivoaxial deformity causing deformative stress injury to the neural axis. Clivoaxial deformity can occur after initial standard suboccipital craniectomy, duraplasty, and C-1 laminectomy for brainstem compression, or severe clivoaxial deformity may be present in conjunction with a Chiari malformation. Clivoaxial deformity and abnormal CXA can be treated with an occipitocervical fusion (OCF). Performing OCF in the setting of a cranial defect can be challenging with currently available instrumentation. The authors describe their recent experience and outcomes in 3 consecutive pediatric patients using the "inside-out" technique for treating clivoaxial deformity and abnormal CXA in the setting of a craniectomy defect to restore stability to the craniocervical junction, while correcting the CXA.

http://thejns.org/doi/abs/10.3171/2014.11.SPINE14484

KEY WORDS Chiari malformation; clivoaxial angle; clivoaxial instability; occipitocervical fusion; craniocervical junction; pediatrics; deformity; cervical

$\mathrm{S}$ UBOCCIPITAL craniectomy with or without expansile duraplasty and possible C-1 laminectomy is commonly used for the treatment of patients with symptomatic Chiari malformation. Although such treatment is generally effective, a subset of patients may develop clivoaxial instability. This is usually heralded by the return of preoperative symptoms and confirmed radiographically by a decreased clivoaxial angle (CXA). It is hypothesized that the decreased CXA results in a tethering phenomenon at the cervicomedullary junction with resultant stretching of medullary and upper cervical spinal cord neuronal fibers. ${ }^{1}$ Consequently, the deformative stress incurred by these fibers may lead to plastic deformation and impaired oxidative metabolism with subsequent development of neurological symptoms. ${ }^{11}$ Restoration of a more anatomical CXA via occipitocervical fusion (OCF) can relieve anterior compression at the cervicomedullary junction and improve neurological function. Bollo et al. in their experience highlighted the diversity of pathology involving patients with Chiari malformations. ${ }^{4}$ In their study, they identified that having a CXA less than $125^{\circ}$ put patients at risk for ultimately requiring OCF to alleviate brainstem compression.

Several techniques exist for stabilization and arthrodesis of the occipitocervical junction. In 1959, Perry and
Nickel described a simple onlay graft technique for OCF. ${ }^{20}$ Postoperatively, patients in this series were placed in a halo vest for 3-4 months until bone fusion was demonstrated on radiological studies. Since that time, bone grafting has been augmented with various internal fixation techniques including contoured rods, cables, plates, and/or screws to provide a rigid environment to enhance fusion. Additionally, modern internal fixation techniques have mitigated the need for postoperative halo-vest immobilization. With the advancement of surgical technique and spinal implants, newer plate-rod and screw systems have led to more biomechanically rigid constructs than that afforded by wiring techniques with an associated higher overall fusion rate. These newer systems generally involve fixating a plate to the suboccipital bone with cortical screws ranging in length from 6 to $10 \mathrm{~mm}$. However, these commonly used methods for occipitocervical fixation require an intact midline keel to decrease the likelihood of screw pullout as the suboccipital bone is significantly thinner laterally, especially in the pediatric population. Furthermore, these constructs are of limited utility in patients who have undegone previous suboccipital craniectomies. ${ }^{18}$

The "inside-out" technique, first described in 1999 by Pait et al., is an alternative technique that can be used for 
achieving rigid fixation of the craniocervical junction and is particularly useful in patients with a previous craniectomy defect. ${ }^{19}$ This technique involves creating two paramedian troughs in the suboccipital bone for the placement of a washer/bolt construct (Fig. 1) under the occipital bone in the epidural space, thus acting as anchoring points for cranial fixation of the rostral construct. We present the use of this OCF technique in a cohort of pediatric patients with symptoms associated with reduced CXA in the setting of decompressive suboccipital craniectomy for the treatment of symptomatic Chiari malformation.

\section{Methods \\ Patient Population}

Three consecutive patients with either prior or concomitant suboccipital craniectomy for Chiari decompression, undergoing OCF using the inside-out technique to stabilize the occipitocervical junction, were retrospectively reviewed. Follow-up data were available for a minimum of 12 months in all 3 patients. All patients had a symptomatic Chiari Type I malformation that was treated surgically with a suboccipital craniectomy and expansile duraplasty. Two patients underwent surgery at an outside institution with initial improvement of preoperative symptoms; however, both patients had a return of their symptoms within 1 year after their index procedure. One of these patients (Case 3) underwent a second decompression procedure at the other institution with duraplasty and cerebellar tonsil resection in an attempt to relieve recurrent symptoms. Two of the 3 patients also suffered from Ehlers-Danlos syndrome. All patients were assessed with preoperative thin-slice CT with coronal and sagittal reconstructions and MRI of the neuraxis. No patient in this series was found to have a syrinx on preoperative imaging.

The CXA was measured as the angle subtended by a line drawn along the dorsal surface of the clivus and a second line drawn along the dorsal surface of the odontoid process of the axis as noted on sagittal reconstructed CT or sagittal MRI. The preoperative and postoperative CXAs were recorded for each patient, along with average correction. Preoperative dynamic imaging was not routinely performed. Routine postoperative static and dynamic cervical radiography was performed at intervals of 12 weeks until evidence of fusion was demonstrated by lack of movement on dynamic radiographs. Perioperative and postoperative records were reviewed, specifically looking for complications related to the surgical procedure and/ or hardware. Postoperatively, patients were treated with a hard cervical collar for a minimum of 6 weeks and were then instructed to initiate weaning use based upon neck pain and symptoms. All cases were performed by the senior surgeon (F.A.S) at Medstar Georgetown University Hospital in Washington, DC.

\section{Surgical Technique}

After induction of general anesthesia, the patient is intubated with an endotracheal tube, intravenous lines are placed, and a Foley catheter is inserted. Perioperative antibiotics are administered and the patient is placed in a
Mayfield head holder and secured to the operating table prone with the neck slightly flexed. The patient is then prepared and draped in normal standardized fashion. A midline incision is made and careful dissection is performed around the previous craniectomy defect, and the outline is clearly demarcated using a combination of Cobb elevators and curettes. The dissection of the occiput is performed laterally in the subperiosteal plane. Dissection is then carried through the avascular midline raphe and the posterior arch of C-1 (if present), and the C-2 spinous process and lamina are exposed in subperiosteal fashion.

Once fully exposed, the superior sulcus of the C-1 lateral masses is carefully dissected and separated from the venous plexus surrounding the vertebral artery in the subperiosteal plane. The medial border of the lateral mass is visualized and a pilot hole is placed in the midpoint of the lateral mass with a drill. Each pilot hole is palpated with a ball probe and judged to be within bone. Fully threaded screws (usually 26-28 $\mathrm{mm}$ in length) are then placed bilaterally using fluoroscopy. This technique has been previously described in detail. ${ }^{24}$

The medial border of the pars interarticularis of C-2 is defined, and pilot holes are placed bilaterally with a drill using standard landmarks. ${ }^{10}$ Each pilot hole is probed to confirm proper bone integrity and appropriate length screws are placed bilaterally.

Next, open reduction of the CXA is then performed under active fluoroscopy. The surgeon breaks sterility to adjust the Mayfield head holder. At this point, the head is slightly extended and distracted to reduce the CXA; this is confirmed using lateral fluoroscopy. Particular attention is directed toward the position of the orbits to ensure the patient is not fixated with an upward gaze.

A mark is placed on the occiput for location of the occipital bolts in line with the position of the C-1 and C-2 screws. A trough is then created from the prior craniectomy defect and carried laterally to the marked end point (Fig. 1A). The occipital bolt is then placed in the epidural space and slid into its final position (Fig. 1B). Rods are cut and contoured to fit into each screw head and bent to conform to the occiput. Each plate is secured to the occiput with a locking nut and final tightened to hand tightness, and the rods are secured to the C-1 and C-2 screws with set caps and final tightened. The stem of the occipital bolt is removed with a rod cutter and trimmed flush with the nut using a metal cutting bur (Fig. 1C).

Rib harvest is then performed in the usual manner. The graft is scored on either side with a fine drill and split in half using a quarter-inch osteotome. The C-2 (and C-1 if present) lamina and occiput are decorticated. The rib autograft is placed posterolaterally from the occiput to the C-2 lamina and held in placed with a 0 Ethibond suture secured around each rod. Demineralized bone matrix was used to supplement the graft and keep the bone in place (Fig. 1D). The wounds are then closed in layers in the usual manner with interrupted absorbable sutures.

\section{Results}

Three pediatric patients ( 2 girls, 1 boy) with an average age of 13.3 years (range 11-15 years) were retrospectively 

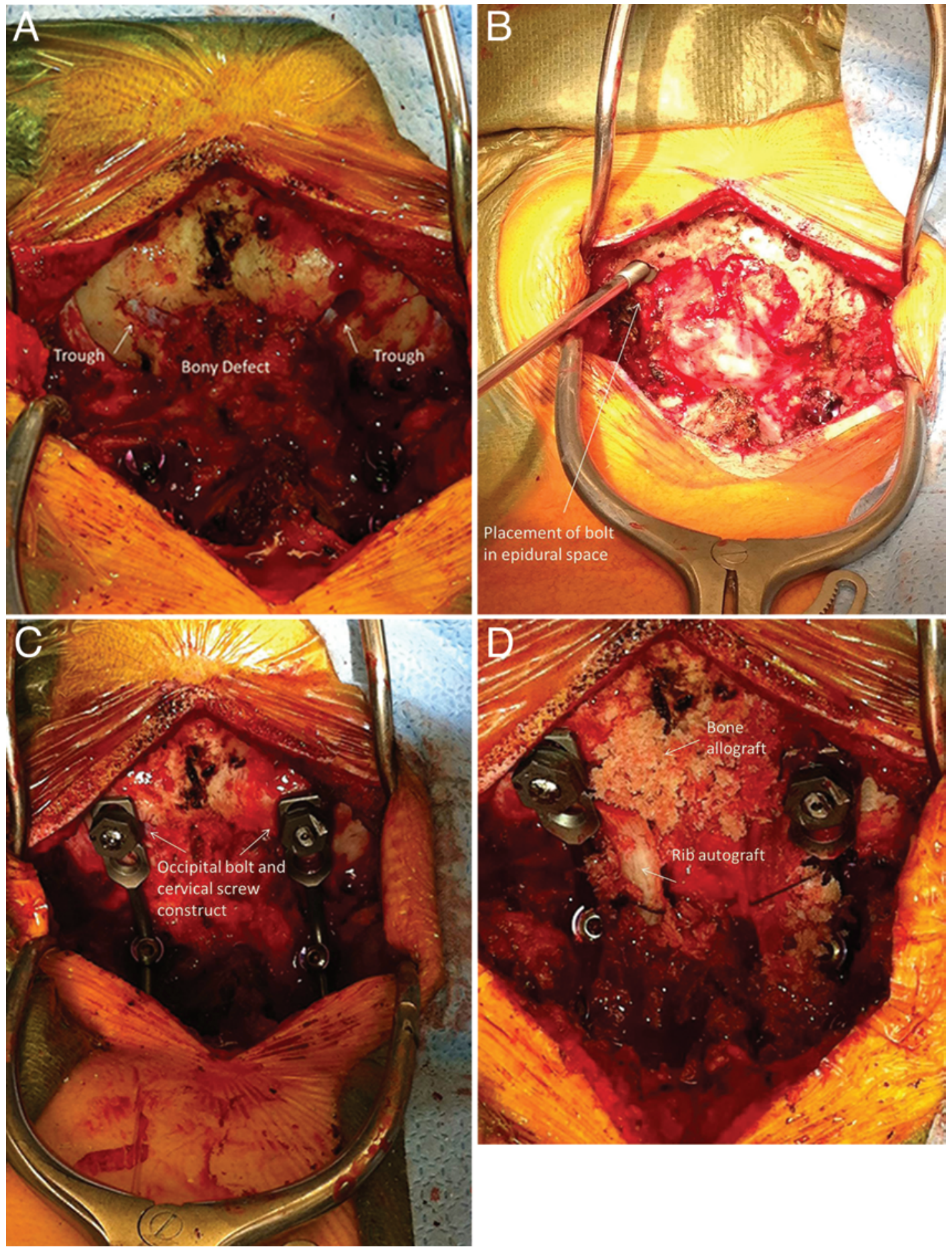

FIG. 1. Intraoperative photographs. A: The occipital troughs created with a high-speed bur and located away from midline (arrows). The final position is planned so it will be in line with the cervical screws. B: The occipital bolt positioned properly in the epidural space of the created trough and in line with the cervical screws (arrow). C: The occipital bolt secured to the cervical screws with a plate, rods, and set screws (arrows). D: The final construct of occipital bolt, screws, plate, and rods, with autograft and allograft (arrows) in place. Figure is available in color online only.

reviewed. Two patients underwent prior suboccipital craniectomy surgery for Chiari decompression at another institution. Both patients presented with recurrent neurological dysfunction with evidence of a flattened CXA. Both patients subsequently underwent OCF with correction of the CXA to a more anatomical alignment. One patient underwent a single-stage suboccipital craniectomy with duraplasty followed by OCF. The inside-out technique was performed for occipital fixation in all patients with rods connected to the $\mathrm{C}-1$ lateral mass and $\mathrm{C}-2$ pars screws. $\mathrm{Rib}$ 
TABLE 1. Pre- and postoperative CXAs, predominant symptoms, and duration of follow-up*

\begin{tabular}{cccclcc}
\hline Case No. & Age $(\mathrm{yrs})$, Sex & Preop CXA $\left(^{\circ}\right)$ & Postop CXA $\left(^{\circ}\right)$ & Symptoms & Prior Surgery & Follow-Up (mos) \\
\hline 1 & $15, \mathrm{~F}$ & 126 & 173 & Headache & Yes & 15 \\
\hline 2 & $14, \mathrm{M}$ & 128 & 153 & Headache & Yes & 12 \\
\hline 3 & $11, \mathrm{~F}$ & 128 & 148 & Vertigo & No & 20 \\
\hline
\end{tabular}

* None of the 3 patients experienced complications.

autograft supplemented with demineralized bone matrix was used for arthrodesis in all cases. The average preoperative CXA was $127.3^{\circ}$ (range $126^{\circ}-128^{\circ}$ ). Postoperative CXA was corrected to an average of $158^{\circ}$ (range $148^{\circ}-$ $173^{\circ}$ ) for an average correction of $30.6^{\circ}$ (range $20^{\circ}-47^{\circ}$ ). There were no perioperative or hardware complications. Bone fusion was noted in all patients by 6 months and none of the patients required postoperative Halo immobilization (Table 1). Additionally, all patients reported resolution of their preoperative symptoms at a minimum of 12-month follow-up.

\section{Case 1}

A 15-year-old girl developed progressively worsening headaches that began to interfere with her activities of daily living. She had not been able to attend school for a year due to the severity of her headaches. This pain had prompted multiple emergency room visits with documentation of worsening blood pressure with neck flexion. A Chiari Type I malformation was diagnosed on MRI. In addition, the CXA was $126^{\circ}$ (Fig. 2A). She underwent a standard suboccipital craniectomy with expansile duraplasty, and, given the abnormal CXA, occipital to C-2 fusion. Her postoperative CXA measured $173^{\circ}$ (Fig. $2 \mathrm{~B}$ and C). Since surgery, she has returned to school with complete resolution of preoperative headaches and blood pressure issues. Stable arthrodesis was demonstrated at 1 year on a CT scan of the cervical spine (Fig. 2D).

\section{Case 2}

A 14-year-old boy, who underwent a suboccipital craniectomy for Chiari Type I malformation 2 years prior at an outside institution, continued to suffer from headaches as well as neck and mid-back pain. These occurred on a daily basis and all of his daily activities were limited as a result of his pain. He also suffered from Ehlers-Danlos syndrome. The patient experienced sleep apnea, chronic fatigue, tremor, and insomnia. He exhausted nonsurgical treatments without improvement. On MRI, he had a CXA of $128^{\circ}$ (Fig. 3A). The patient underwent occiput to C-2 fusion. His postoperative CXA measured $153^{\circ}$ (Fig. 3B and C). After surgery, his headaches improved significantly. Additionally, he had decreased tremor, and subjective improvement of his cognition and attentiveness. A CT scan at 8 months demonstrated bridging bone from the occiput to C-2 lamina (Fig. 3D and E).

\section{Case 3}

An 11-year-old girl with a history of Ehlers-Danlos syndrome, longstanding headaches, and ataxic gait had undergone a prior suboccipital craniectomy with a subsequent revision surgery at an outside institution 1 year later with duraplasty and cauterization of the cerebellar tonsils for recurrence of her symptoms. Unfortunately, her symptoms continued and she developed severe dizziness that prevented her from sitting or standing for prolonged periods, forcing her parents to enroll her in a special school that allowed her to take classes lying down. She had brief symptomatic relief with the use of a rigid cervical collar. There was evidence of clivoaxial deformity on preoperative imaging. Her CXA measured $128^{\circ}$ (Fig. 4A) before surgery and improved to $148^{\circ}$ postoperatively (Fig. $4 \mathrm{~B}$ and C). After surgery, her dizziness and headaches resolved completely and her gait improved. She was able to return to her regular school by 3 months following surgery.
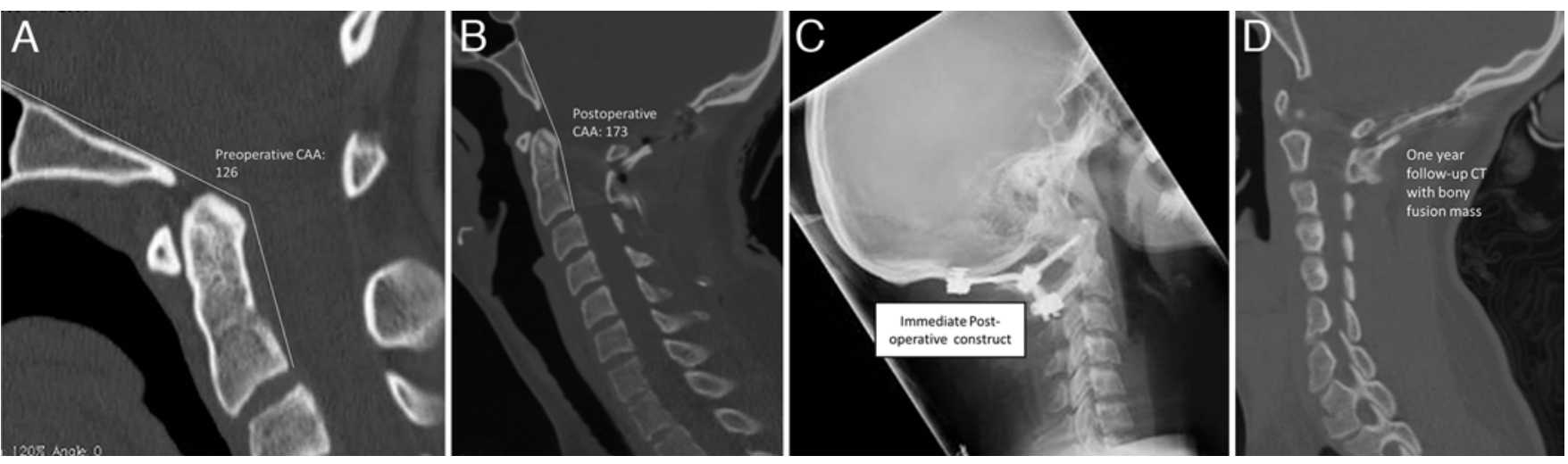

FIG. 2. Case 1. Preoperative (A) and postoperative (B) sagittal CT scans demonstrate the measured $C X A\left(126^{\circ}\right.$ and $173^{\circ}$, respectively). An immediate postoperative lateral plain radiograph of the cervical spine shows appropriate hardware placement (C). $A$ 1-year postoperative sagittal CT scan of the cervical demonstrates fusion mass (D). CAA = clivoaxial angle. 

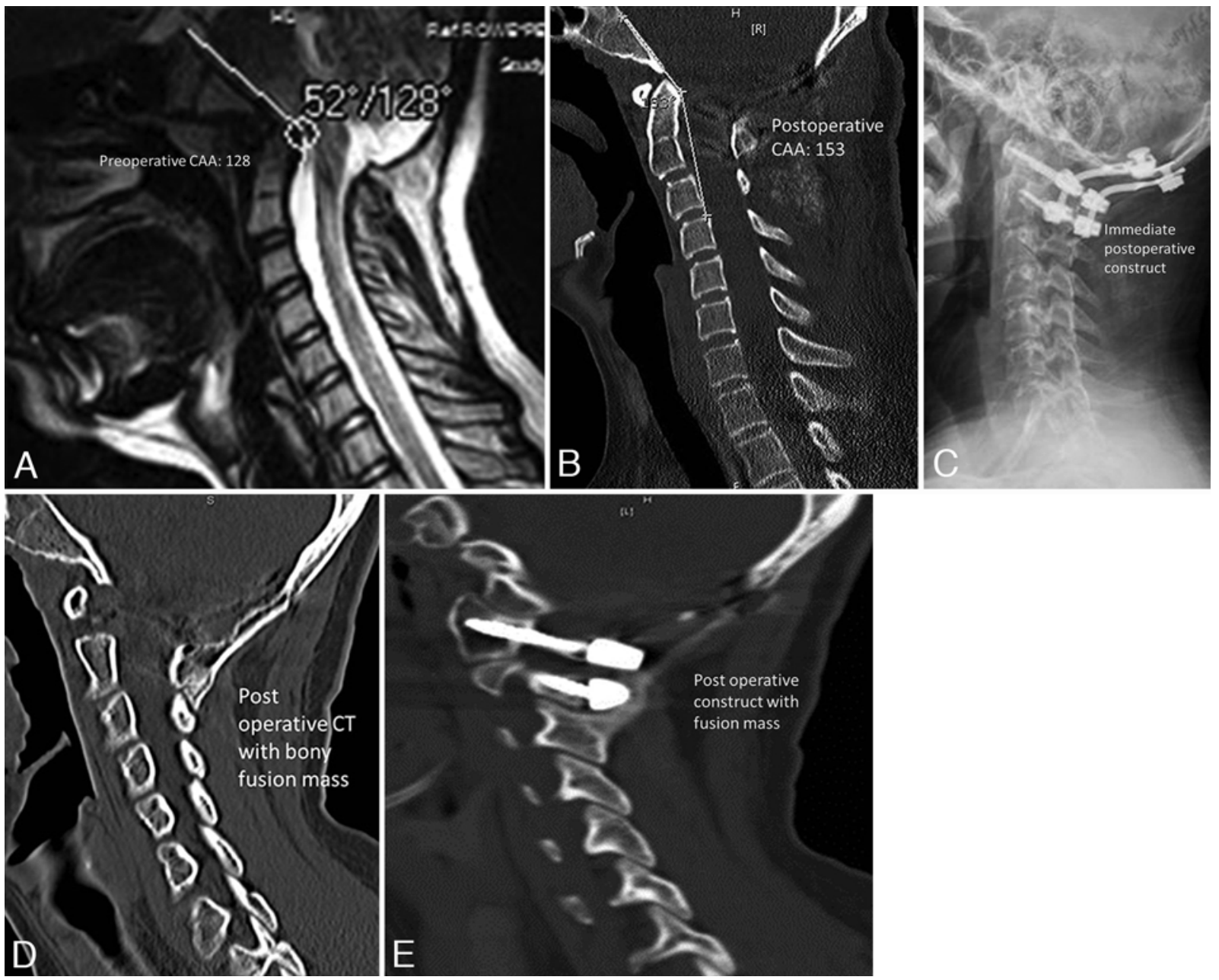

FIG. 3. Case 2. Preoperative sagittal MR image (A) and postoperative sagittal CT scan (B) demonstrate the measured CXA $\left(128^{\circ}\right.$ and $153^{\circ}$, respectively). An immediate postoperative lateral plain radiograph of the cervical spine shows appropriate hardware placement (C). Eight-month postoperative lateral CT scans of the cervical spine demonstrate evidence of appropriate hardware placement and bone fusion mass ( $D$ and $E$ ).

\section{Discussion}

Recurrent or persistent symptoms following suboccipital craniectomy for Chiari malformation should raise the suspicion for clivoaxial deformity as an underlying cause. This deformity results in kinking or direct compression of the anterior brainstem and causes deformative stress of the neural elements. ${ }^{1}$ By applying finite element analysis to a group of pediatric patients with Chiari malformation and clivoaxial deformity, Henderson et al. demonstrated increased stress in the upper medulla in the region of the dorsal motor nuclei, nucleus solitaries, and in the posterior and lateral columns at the C-2 level. ${ }^{11}$ These changes were postulated to correlate with the protean symptoms that can manifest in these patients. Additionally, central neurons are particularly susceptible to stretch injury. ${ }^{1}$ Patients can present with signs of cervical myelopathy, bulbar dysfunction, as well as severe neck pain and headaches. It has been recognized that Chiari decompression as well as correction of the CXA results in superior clinical outcomes, especially if the CXA is less than $130^{\circ} .4,12$ Although a nor- mal value for the CXA has not been clearly defined, generally angulation less than $130^{\circ}$ results in brainstem kinking or "medullary kyphosis," and angles greater than $145^{\circ}$ improve clinical symptoms from clivoaxial deformity.11,14

Knowledge of the anatomy at the occipitocervical junction and the complex biomechanical forces incurred to this area is required when performing an OCF. Furthermore, the anatomical constraints of the thin, squamosal, occipital bone may inhibit rostral construct stability due to limited screw purchase. Several studies have been published evaluating occipital morphometry. Ebraheim et al. measured the occipital bone thickness in 52 adult cadaveric skulls and measured using an electronic caliper demonstrating an average thickness of $11.5 \mathrm{~mm}$ for men, $9.7 \mathrm{~mm}$ for women (range $9.7-15.1 \mathrm{~mm}$ ) at the midline occipital keel. ${ }^{8}$ Additionally, it was noted that the occipital bone decreased in thickness laterally from the external occipital protuberance. In a study of pediatric patients aged 2 to 6 using CT, Geck et al. noted that the bone thickness was greatest at the external occipital protuberance, ranging between $8.60 \mathrm{~mm}$ and $10.54 \mathrm{~mm} .{ }^{9}$ These studies dem- 

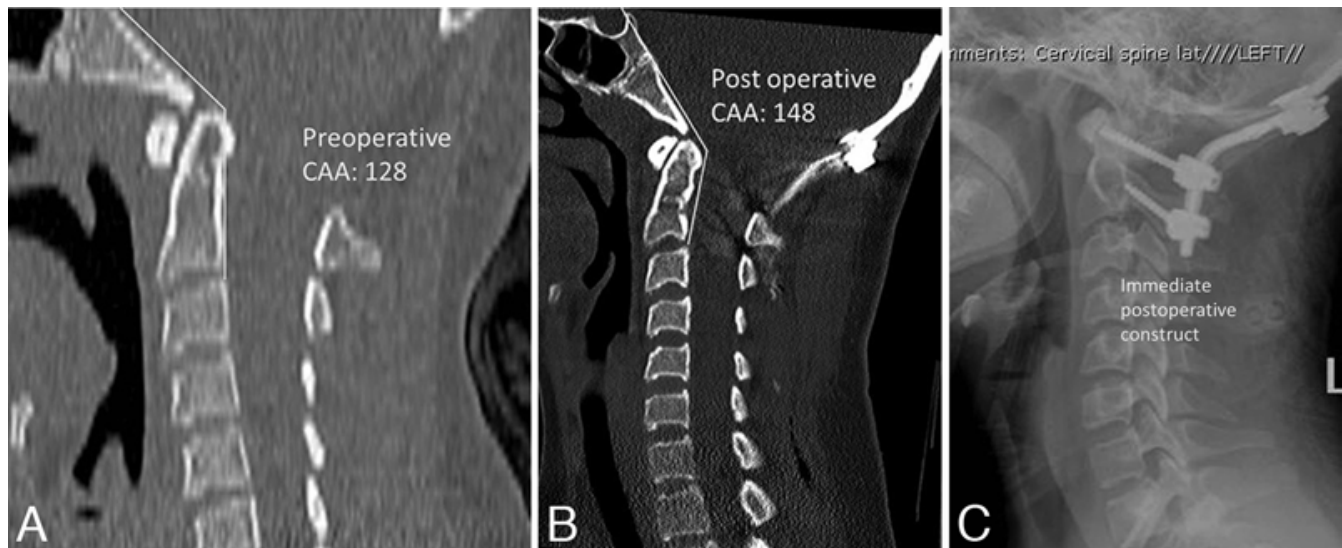

FIG. 4. Case 3. Preoperative (A) and postoperative (B) sagittal CT scans show the measured CXA $\left(128^{\circ}\right.$ and $148^{\circ}$, respectively). An immediate postoperative lateral $\mathrm{C}$-spine plain films shows evidence of appropriate hardware placement (C).

onstrate that the ideal location for plate-screw fixation is at the midline occipital keel due to the thicker bone in this region. Therefore, most available instrumentation systems use plates that take advantage of the thick midline keel. However, these systems often cannot be used in patients who have undergone prior suboccipital craniectomy for Chiari malformation.

Complications related to newer OCF constructs were reported in a meta-analysis conducted by Bhatia et al. ${ }^{3}$ and separately by Winegar et al. ${ }^{27}$ Complications included vertebral artery injury, wound infections or dehiscence, CSF leak, cerebellar subdural hematoma, misplaced screws, and venous sinus injury. Overall, fusion rates are generally greater than $90 \%$ (range $74 \%-100 \%$ ) and were noted regardless of OCF technique (i.e., rod/wires, plates/screws, onlay/wires, and rod/screws).

The inside-out technique was originally described by Pait et al. in 1999. ${ }^{19}$ This technique was used for OCF in a total of 26 patients, 6 of whom were children. Although this technique was used for a variety of pathological diseases, these investigators concluded that the technique is a safe and effective surgical technique for providing rigid occipitocervical fixation with minimal complications. Sandhu et al. performed 21 operations in adults with rheumatoid arthritis utilizing the inside-out technique for OCF. ${ }^{22}$ They reported a fusion rate of $100 \%$ with no observed cranial settling at an average follow-up of 25.5 months. Additionally, there were no cerebellar hematomas resulting from the placement of the cranial bolts. Sribnick and colleagues performed 21 surgeries using the inside-out technique in pediatric patients for a variety of pathologies. ${ }^{23}$ Fusion rate was noted to be $100 \%$ at a mean follow-up of 27 months. These authors reported 5 complications: 1 was a surgical site infection, 2 were in patients who required tracheostomies, and 2 were related to screw pullout but did not require reoperation because of evidence of bone fusion. More recently, Lu et al., in a review of OCF surgical techniques, noted that they prefer the inside-out technique in the pediatric population for the reasons mentioned above. ${ }^{18}$ Although the inside-out technique is not novel, we emphasize its benefits in the setting of a prior craniectomy defect and thin bones of the pediatric population. Caglar et al. compared the biomechanical pullout strength of inside-out bolts with cables and standard screws. ${ }^{5}$ Using a saw-bone model, they tested each group for pullout strength. They showed an average resistance of $1383 \mathrm{~N}$ for the 14-mm inside-out bolt, $636 \mathrm{~N}$ for multifilament cables, and $457 \mathrm{~N}$ for a $10-\mathrm{mm}$ traditional screw system. These data show superior pullout strength using the inside-out technique.

There are several technical aspects to consider when performing OCF in patients with a prior midline craniectomy defect. As stated, most standard OCF systems require an intact midline keel for adequate occipital fixation. The method employed in this study does not require intact anatomy to allow placement of instrumentation. Furthermore, this technique involves aligning the occipital bolts/ washers midline to lateral, which facilitates rod placement to the caudal cervical screws, and may provide more rigid fixation. The midline occipital sinus may remain patent in up to $10 \%$ of the pediatric population, which may lead to an increased risk of blood loss when using the midline keel for screw fixation..$^{19}$ Additionally, the dura in the pediatric population is considered to be more vascular, which can lead to additional bleeding when using currently available methods of screw placement without direct visualization of the underlying dura. In contrast, the inside-out technique circumvents the midline keel, thus avoiding the occipital sinus while allowing for direct visualization of the dura at all times. It is our opinion that this technique suited these selected patients, in particular because of the large craniectomy defect and thin bone. There may be cases in which midline screws can be placed below the inion with other occipital plating systems if the bone defect is not too large. One must carefully consider the location and profile in these cases to avoid postoperative pain or skin erosion.

Although patients could be positioned with the CXA reduced from the start of the surgery, we find it advantageous to maintain a slight degree of flexion or neutral fixation initially to facilitate exposure and placement of screws. Also, if there is any compression from a Chiari malformation or basilar invagination, initial positioning to reduce the CXA could further cause brainstem compression and result in neurological deficits. Intraoperative reduction of the CXA in these cases, after decompression, is critical to avoiding neurological injury while maximizing 
correction of the CXA. ${ }^{12}$ Extension and distraction alter the relationship between the clivus and $\mathrm{C}-2$ to afford optimum correction of the CXA.

In our series, a hard cervical collar was routinely used for the first 6-8 weeks, and then was discontinued unless the patient was experiencing additional neck pain or muscle spasm. MRI was not routinely performed postoperatively due to the absence of clinical need. This is in contrast to older OCF constructs that necessitated the use of an external orthosis such as a Halo vest, which may add significant morbidity. This is not unique to the inside-out technique, as newer systems additionally provide improved rigid fixation when compared with prior semirigid wiring systems. We also used a rib autograft instead of iliac crest harvesting. The curvature of the rib allows for a better approximation to the occipitocervical junction. Furthermore, there is less donor site morbidity associated with harvesting a rib graft along with a potentially decreased time to fusion. ${ }^{6}$ This technique employs a low-profile construct that minimizes stress on the skin, which helps avoid wound breakdown and infection.

More recently, there have been several case reports documenting the use of occipital condylar screws for OCF. Initially described in 2008 by La Marca et al., ${ }^{15}$ then further investigated by Kosnik-Infinger et al. ${ }^{13}$ and Uribe and colleagues $^{16,17,25}$ via radiological and cadaveric analysis, the technique has since been shown to be a viable method to fuse the occiput and cervical spine. Specifically, it has been used in a pediatric setting of craniocervical instability from tumor surgery, craniovertebral anomalies, and prior suboccipital decompression. ${ }^{2,13}$ There are biomechanical data demonstrating that condylar screws provide stiffness in flexion, extension, and lateral and axial support equivalent to that provided with the currently available constructs for OCF. ${ }^{26}$ The technique involves placing occipital condyle screws, usually with the aid of neuronavigation. ${ }^{21}$ It can be a useful adjunct technique when there is not enough occipital bone to allow for fixation, but the regional anatomy can be varied, and in up to $20 \%$ of the population may be contraindicated. In addition, there can be prominent venous bleeding, which is disadvantageous in the pediatric population; its advantages are a lower profile construct, a decreased lever arm, and the opportunity to use a larger screw size. ${ }^{16}$

\section{Conclusions}

There are limited options for performing OCF in the setting of a cranial defect. The inside-out technique allows for safe occipital fixation without the requirement of an intact midline keel. Additionally, this technique may mitigate some of the complications associated with occipital screw placement. Lastly, this technique can be used to provide rigid fixation to correct an abnormal CXA in addition to augmenting arthrodesis of the occipitocervical junction.

\section{References}

1. Arundine M, Aarts M, Lau A, Tymianski M: Vulnerability of central neurons to secondary insults after in vitro mechanical stretch. J Neurosci 24:8106-8123, 2004

2. Bekelis K, Duhaime AC, Missios S, Belden C, Simmons N: Placement of occipital condyle screws for occipitocervical fixation in a pediatric patient with occipitocervical instability after decompression for Chiari malformation. J Neurosurg Pediatr 6:171-176, 2010

3. Bhatia R, Desouza RM, Bull J, Casey ATH: Rigid occipitocervical fixation: indications, outcomes, and complications in the modern era. J Neurosurg Spine 18:333-339, 2013

4. Bollo RJ, Riva-Cambrin J, Brockmeyer MM, Brockmeyer DL: Complex Chiari malformations in children: an analysis of preoperative risk factors for occipitocervical fusion. $\mathbf{J}$ Neurosurg Pediatr 10:134-141, 2012

5. Caglar YS, Torun F, Pait TG, Hogue W, Bozkurt M, Ozgen S: Biomechanical comparison of inside-outside screws, cables, and regular screws, using a sawbone model. Neurosurg Rev 28:53-58, 2005

6. Cohen MW, Drummond DS, Flynn JM, Pill SG, Dormans JP: A technique of occipitocervical arthrodesis in children using autologous rib grafts. Spine (Phila Pa 1976) 26:825829, 2001

7. Dvorak MF, Fisher C, Boyd M, Johnson M, Greenhow R, et al: Anterior occiput-to-axis screw fixation. Part I: a case report, description of a new technique, and anatomical feasibility analysis. Spine (Phila Pa 1976) 28:E54-E60, 2003

8. Ebraheim NA, Lu J, Biyani A, Brown JA, Yeasting RA: An anatomic study of the thickness of the occipital bone. Implications for occipitocervical instrumentation. Spine (Phila Pa 1976) 21:1725-1730, 1996

9. Geck MJ, Truumees E, Hawthorne D, Singh D, Stokes JK, Flynn A: Feasibility of rigid upper cervical instrumentation in children: tomographic analysis of children aged 2 to 6 . J Spinal Disord Tech 27:E110-E117, 2014

10. Harms J, Melcher RP: Posterior C1-C2 fusion with polyaxial screw and rod fixation. Spine (Phila Pa 1976) 26:2467-2471, 2001

11. Henderson FC, Wilson WA, Mott S, Mark A, Schmidt K, Berry JK, et al: Deformative stress associated with an abnormal clivo-axial angle: a finite element analysis. Surg Neurol Int 1:30, 2010

12. Kim LJ, Rekate HL, Klopfenstein JD, Sonntag VKH: Treatment of basilar invagination associated with Chiari I malformations in the pediatric population: cervical reduction and posterior occipitocervical fusion. J Neurosurg 101 (2 Suppl):189-195, 2004

13. Kosnik-Infinger L, Glazier SS, Frankel BM: Occipital condyle to cervical spine fixation in the pediatric population. $\mathbf{J}$ Neurosurg Pediatr 13:45-53, 2014

14. Kubota M, Yamauchi T, Saeki N: Surgical results of foramen magnum decompression for Chiari type 1 malformation associated with syringomyelia: a retrospective study on neuroradiological characters influencing shrinkage of syringes. Spinal Surg 18:81-86, 2004

15. La Marca F, Zubay G, Morrison T, Karahalios D: Cadaveric study for placement of occipital condyle screws: technique and effects on surrounding anatomic structures. J Neurosurg Spine 9:347-353, 2008

16. Le TV, Burkett C, Ramos E, Uribe JS: Occipital condyle screw placement and occipitocervical instrumentation using three-dimensional image-guided navigation. J Clin Neurosci 19:757-760, 2012

17. Le TV, Dakwar E, Hann S, Effio E, Baaj AA, Martinez C, et al: Computed tomography-based morphometric analysis of the human occipital condyle for occipital condyle-cervical fusion. J Neurosurg Spine 15:328-331, 2011

18. Lu DC, Roeser AC, Mummaneni VP, Mummaneni PV: Nuances of occipitocervical fixation. Neurosurgery 66 (3 Suppl):141-146, 2010

19. Pait TG, Al-Mefty O, Boop FA, Arnautovic KI, Rahman S, Ceola W: Inside-outside technique for posterior occipitocervical spine instrumentation and stabilization: preliminary results. J Neurosurg 90 (1 Suppl):1-7, 1999 
20. Perry J, Nickel VL: Total cervicalspine fusion for neck paralysis. J Bone Joint Surg Am 41-A:37-60, 1959

21. Rammos S, Klopfenstein J, Augspurger L, Wang H, Wagenbach A, Poston J, et al: Conversion of external ventricular drains to ventriculoperitoneal shunts after aneurysmal subarachnoid hemorrhage: effects of site and protein/red blood cell counts on shunt infection and malfunction. J Neurosurg 109:1001-1004, 2008 (Erratum in J Neurosurg 110:196, 2009)

22. Sandhu FA, Pait TG, Benzel E, Henderson FC: Occipitocervical fusion for rheumatoid arthritis using the inside-outside stabilization technique. Spine (Phila Pa 1976) 28:414-419, 2003

23. Sribnick EA, Dadashev VY, Brahma B, Wrubel DM: The use of inside-outside screws for occipitocervical fusion in pediatric patients. J Neurosurg Pediatr 10:392-397, 2012

24. Thomas JA, Tredway T, Fessler RG, Sandhu FA: An alternate method for placement of C-1 screws. J Neurosurg Spine 12:337-341, 2010

25. Uribe JS, Ramos E, Vale F: Feasibility of occipital condyle screw placement for occipitocervical fixation: a cadaveric study and description of a novel technique. J Spinal Disord Tech 21:540-546, 2008

26. Uribe JS, Ramos E, Youssef AS, Levine N, Turner AW, John- son WM, et al: Craniocervical fixation with occipital condyle screws: biomechanical analysis of a novel technique. Spine (Phila Pa 1976) 35:931-938, 2010

27. Winegar CD, Lawrence JP, Friel BC, Fernandez C, Hong J, Maltenfort M, et al: A systematic review of occipital cervical fusion: techniques and outcomes. J Neurosurg Spine 13:5-16, 2010

\section{Author Contributions}

Conception and design: all authors. Acquisition of data: all authors. Analysis and interpretation of data: all authors. Drafting the article: all authors. Critically revising the article: all authors. Reviewed submitted version of manuscript: all authors. Statistical analysis: Felbaum, Spitz. Administrative/technical/material support: all authors. Study supervision: all authors.

\section{Correspondence}

Faheem Sandhu, Department of Neurosurgery, Medstar Georgetown University Hospital, 3700 Reservoir Rd. NW, 7 PHC, Washington, DC 20007. email: fasandhu@aol.com. 